\title{
Supporting Teachers' Learning about Mathematical Modeling
}

\author{
June L. Gastón ${ }^{1} \&$ Barbara A. Lawrence ${ }^{1}$ \\ Department of Mathematics, Borough of Manhattan Community College of the City University of New York \\ Correspondence: June L. Gastón, Department of Mathematics, Borough of Manhattan Community College of the \\ City University of New York, 199 Chambers Street, New York NY 11411-1214, USA. Tel: 212-220-1342. E-mail: \\ jgaston@bmcc.cuny.edu
}

Received: July 29, 2015 Accepted: August 13, 2015 Online Published: October 16, 2015

doi:10.5539/ijsp.v4n4p1 URL: http://dx.doi.org/10.5539/ijsp.v4n4p1

\begin{abstract}
In the United States, one of the Standards for Mathematical Practice of the Common Core Curriculum (Common Core State Standards Initiative, 2010) is Model with mathematics. This standard requires that students be taught in a manner that will enable them to "apply the mathematics they know to solve problems arising in everyday life, society, and the workplace" (p. 7). However many prospective and practicing teachers acquire a pedagogical style that does not support this standard. To promote higher levels of student thinking associated with mathematical modeling, teachers must thus be taught not only what mathematical modeling is, but how it can be effectively incorporated in their lessons and presented to their classes. Teacher training should also include how to develop rubrics for assessment, among which are rubrics that enable students to demonstrate mathematical modeling proficiency in different ways. In this research, the topics addressed include ways professional development can help in-service teachers appreciate the importance of mathematical modeling tasks; concerns about teacher backgrounds in mathematical modeling; and the most effective ways for improving in-service teachers' knowledge of mathematical modeling and their teaching of mathematical modeling. While the primary focus of this research is on teacher education and training in the United States, the findings from both domestic and international research are clearly significant for those who are responsible for various aspects of teacher preparation worldwide.

Common Core State Standards Initiative. (2010). Common Core State Standards for Mathematics (CCSSM). Washington, DC: National Governors Association Center for Best Practices and the Council of Chief State School Officers.
\end{abstract}

Keywords: mathematical modeling, mathematical pedagogy, mathematics curriculum standards, mathematics teacher education

\section{Introduction}

In the United States, one of the Standards for Mathematical Practice of the Common Core Curriculum (Common Core State Standards Initiative, 2010) is Model with mathematics. This standard requires that students be taught in a manner that will enable them to "apply the mathematics they know to solve problems arising in everyday life, society, and the workplace" (p. 7). However many prospective and practicing teachers acquire a pedagogical style that does not support this standard. To promote higher levels of student thinking associated with mathematical modeling, teachers must thus be taught not only what mathematical modeling is, but how it can be effectively incorporated in their lessons and presented to their classes. Teacher training should also include how to develop rubrics for assessment, among which are rubrics that enable students to demonstrate mathematical modeling proficiency in different ways.

This study presented both domestic (U.S.) and international research-based suggestions that can support teacher efforts to better understand, learn, teach and evaluate pertinent aspects of mathematical modeling. The research is important because better qualified teachers tend to produce better trained students. Such teachers are needed to teach the more demanding K-12 Common Core State Standards in Mathematics (CCSSM), especially the challenging mathematical modeling standard, and to help prepare students meet demanding qualifications for science, technology, engineering and mathematics (STEM) careers.

It is expected that the results of this study will assist mathematics teacher educators, teacher trainers, teacher leaders, teacher mentors, curriculum specialists, instructional developers, mathematics education researchers, 
and those responsible for faculty development and other aspects of teacher preparation, to design and improve instruction in the challenging area of mathematical modeling.

Several publications highlight how and why mathematical models and modeling has grown in importance in the United States, why mathematical models and modeling have gained prominence in the educational curriculum, and why it is important that qualified teachers effectively teach mathematical models and modeling.

The National Council of Teachers of Mathematics (NCTM) is the largest professional organization concerned with policies and practices in the teaching of mathematics in grades Kindergarten through 12 (K-12). The NCTM Principles and Standards for School Mathematics (2000) is a comprehensive and coherent set of standards for all K-12 students. A goal of the Standards was to provide a resource to help educators better prepare more students for college coursework and 21st century STEM careers. The Standards also recognized the need for both well-qualified teachers and institutional support that would enable them to effectively implement the curriculum and assess its effectiveness. There are two types of standards, content standards that indicate what students should know, and process standards that indicate how students should learn and apply the content. The five content standards are (1) Number and Operations, (2) Algebra, (3) Geometry. (4) Measurement, and (5) Data Analysis and Probability. The five process standards are (1) Problem Solving, (2) Reasoning and Proof, (3) Communication. (4) Connections, and (5) Representations. A later publication, NCTM Curriculum Focal Points for Prekindergarten through Grade 8 Mathematics: A Quest for Coherence (2006), endeavored to identify crucial mathematical topics for each grade level, and how they should relate to one another across the grades. The aim was to promote better organization, and to eliminate the repetition and redundancy that inhibits efficient teaching of curriculum topics. Focal Points served as an important resource for CCSSM developers, and can still be used as a resource to examine mathematics topics and strands in lesson and curriculum development. However mathematical modeling did not become an important part of the K-12 curriculum until the CCSSM were developed.

According to Blum (2011), modeling is important for students because "Mathematical models and modelling are everywhere around us, often in connection with powerful technological tools. Preparing students for responsible citizenship and for participation in societal developments presupposes modelling competency."(p. 19). Niss (2012) affirmed that

"A major reason why mathematics is the world's single largest educational subject is the fact that mathematics is applied in a multitude of different ways in a huge variety of extra-mathematical subjects, fields and practice areas. Every time mathematics is used to deal with issues, problems, situations and contexts in domains outside of mathematics, mathematical models and modelling are necessarily involved, be it implicitly or explicitly." (p. 49).

In 2012, the Society for Industrial and Applied Mathematics (SIAM), a professional organization that has organized mathematical modeling contests for high school students since 2006, held its first Modeling Across the Curriculum Workshop. The SIAM working groups of STEM professionals proposed recommendations to: (1) expand modeling at the K-12 grade levels; (2) develop a one-semester or one-year modeling course for the high school level; (3) develop modeling-based curricula for the college level; and (4) develop a repository of educational materials (e.g., lesson plans, articles, websites, and videos) for various levels of mathematical modeling instruction.

According to the workshop report, the ultimate goal of these recommendations was to channel people into STEM disciplines beginning at the elementary school level, continuing through the college level, then into the workforce (SIAM, 2012).

An undergraduate STEM education report, Engage to Excel: Producing One Million Additional College Graduates with Degrees in Science, Technology, Engineering, and Mathematics released by the President's Council of Advisors on Science and Technology (PCAST), called for increasing student preparedness for STEM majors; it also called for improving STEM education in the first two years of college. PCAST reported a need for approximately one million more U.S. college graduates for projected openings in STEM careers during the next decade. The report included recommendations that aim to promote better teaching practices, discovery-based research courses, and postsecondary mathematics preparation (PCAST, 2012).

A project report of the National Research Council (NRC), The Mathematical Sciences in 2025, identified the importance of interdisciplinary STEM research and mathematical modeling as important components of academic training for resolving increasingly complex problems of the $21^{\text {st }}$ century. The report called for a more comprehensive outlook concerning modern STEM careers, and identified mathematics as the discipline providing the strong connections that serve as the foundation for interdisciplinary research (NRC, 2013). 
A second SIAM Modeling Across the Curriculum Workshop, held in 2014, extended the work of the first by having three working groups continue the work on mathematical modeling for the K-12 level, and develop and promote the use of high school curricular materials. They also began to explore two pathways to improve undergraduate STEM education through (1) informative reports about mathematical modeling that target stakeholders and mathematicians, and (2) alliances with other organizations to form a special interest group for applied mathematics education. The workshop report noted that in the CCSSM, (Common Core State Standards Initiative, 2010), mathematical modeling is the only topic that is a conceptual category, a standard for mathematical practice, and a standard for science. The report stipulated that through proficiency in mathematical modeling, K-12 students can prepare for majors in social, financial and life science majors, and most importantly for STEM college majors and careers. To facilitate interdisciplinary work, especially in related areas such as modeling, information science, and computational mathematics, the report suggested that it is better to avoid creating different terms for equivalent ideas and simply use the common language of mathematics (SIAM, 2014).

The Mathematical Association of America (MAA), through its Committee on the Undergraduate Program in Mathematics (CUPM), published the 2015 CUPM Curriculum Guide to Majors in the Mathematical Sciences (Zorn, 2015). The Guide includes several cognitive and content recommendations to facilitate the development or modification of college mathematics programs. Among the cognitive recommendations is one that refers to appropriate program activities to promote thinking and communications skills; such activities include "identify and model essential features of a complex situation, modify models as necessary for tractability, and draw useful conclusions" (p.10). Among the content recommendations for the major in mathematical sciences is one that refers to the inclusion of "concepts and methods from data analysis, computing, and mathematical modeling" (p.11) and another that suggests students majoring in mathematical sciences "experience mathematics from the perspective of another discipline" (p. 12). In discussing curricular change, the Guide envisions that the implementation of the Common Core State Standards "will significantly change the preparation of incoming college students and will necessitate changes in the preparation of pre-service teachers" (p. 2). The Guide's Program Areas include Teacher Education, and related recommendations of the MAA's Committee on the Education of Teachers (COMET) that (1) pre-service high school teachers get ample training to teach the CCSSM content focused on data collection and interpretation, and (2) that their program include a two-semester sequence of courses in introductory statistics and statistical methods. The Guide's Course Areas include Modeling, and its Course Area Study Group (CASG) agreed that modeling is an essential component of the K-12 mathematics curriculum. The CASG Modeling report (2015) recommends that “...colleges and universities that prepare future teachers will want to ensure that their mathematics curriculum is configured in such a way that preservice teachers gain meaningful experience with modeling and applications of mathematics, either through modeling activities integrated into the core mathematics curriculum, through a dedicated course focused on mathematical modeling, or both." (p. 8).

\section{Method}

This study used the methodology of evaluation research to find ways that support teachers in their efforts to learn, teach and assess mathematical modeling. Both domestic (U.S.) and international references were examined, including government publications, publications of professional organizations, and peer-reviewed journals. The research discussed many issues and perspectives involved in improving teacher training in mathematical modeling. The research results have thus been organized into three general topics for better coherence:

1. Mathematical knowledge for teaching (MKT) that supports effective teaching of mathematical modeling or modeling mathematics

2. In-service and pre-service teacher education that supports better understanding of mathematical modeling and the modeling process

3. Professional development of in-service teachers that recognizes their diverse academic and professional expertise, and provides ways to improve and support their understanding of mathematical modeling, including teaching and assessing it

\section{Results}

\subsection{Mathematical Knowledge for Teaching (MKT) That Supports Effective Teaching of Mathematical Modeling or Modeling Mathematics}

MKT refers to unique mathematical knowledge for teachers of a specific grade level. It consists of subject matter knowledge and pedagogical content knowledge (Ball, Thames, \& Phelps, 2008). 


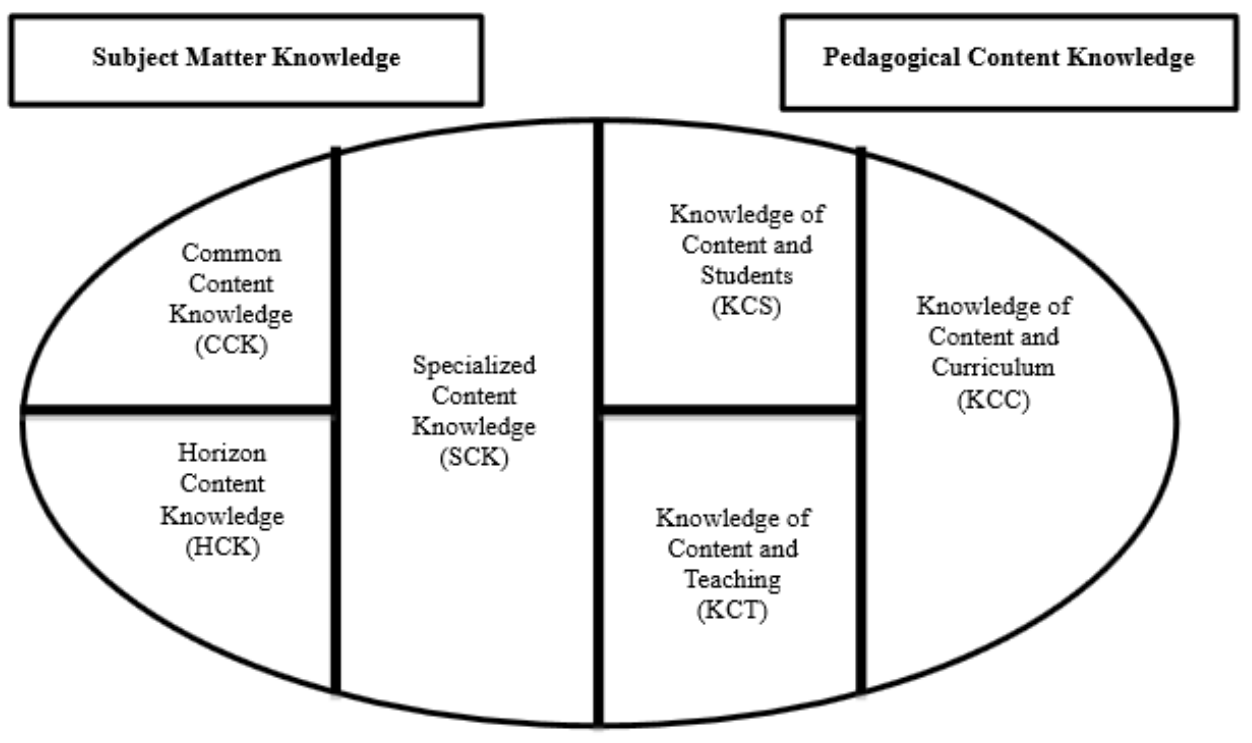

Figure 1. Model of Teachers' Mathematical Knowledge for Teaching (Ball et al., 2008, p. 403).

In the United States, some teacher preparation programs address MKT by requiring that students take general mathematics courses. Ball and colleagues (2008) noted that crucial aspects of teaching mathematics are rarely addressed in those types of courses. In their research, they concluded that certain MKT aspects (e.g., SCK, KCT and $\mathrm{KCC}$ ) need to be addressed in mathematics courses especially for teachers to help them develop better understanding of the mathematics they will teach. Another acronym, TPACK, describes updated teacher knowledge; it consists of technology, pedagogy, and content knowledge (Niess, 2015).

In undergraduate elementary education programs, one or two mathematics courses may be offered. Ideally, subject matter and pedagogy focus on topics that include real numbers, data analysis and probability, geometry and measurement, and algebra. Prospective middle school and high school teachers require progressively more preparation, thus prior level MKT serves as the groundwork for subsequent topics (e.g., statistics, algebra, geometry, trigonometry, and calculus, with appropriate technological skills). Since college coursework provides foundational MKT for pre-service teachers, such courses need to incorporate mathematical modeling. In their research, Ferri and Blum (2009) provide four dimensions of this MKT specifically for modeling:

“... (1) Theoretical competency (knowledge about modelling cycles, about goals/perspectives for modelling and about types of modelling tasks), (2) Task related competency (ability to solve, analyze and create modelling tasks), (3) Teaching competency (ability to plan and perform modelling lessons and knowledge of appropriate interventions during pupils' modelling processes), and (4) Diagnostic competency (ability to identify phases in pupils' modelling processes and to diagnose pupils' difficulties during such processes)." (p. 2047).

To maximize MKT, they recommended broad opportunities to experience modeling on both a theoretical and practical level.

\subsection{In-service and Pre-service Teacher Education That Supports Better Understanding of Mathematical Modeling and the Modeling Process}

In general, the training of both pre-service and in-service teachers must also help them understand what a mathematical model is, why mathematical modeling is important and what classroom strategies and challenges are involved in the K-12 development, use and assessment of mathematical modeling (Sole, 2013).

In the Common Core State Standards for Mathematics (CCSSM, Common Core State Standards Initiative, 2010), the basic modeling cycle 
"involves (1) identifying variables in the situation and selecting those that represent essential features, (2) formulating a model by creating and selecting geometric, graphical, tabular, algebraic, or statistical representations that describe relationships between the variables, (3) analyzing and performing operations on these relationships to draw conclusions, (4) interpreting the results of the mathematics in terms of the original situation, (5) validating the conclusions by comparing them with the situation, and then either improving the model or, if it is acceptable, (6) reporting on the conclusions and the reasoning behind them. Choices, assumptions, and approximations are present throughout this cycle." (p. 72).

Mathematical modeling is a CCSSM Standard for Mathematical Practice for all grades, and is a required conceptual category for high school.

Progressions for the CCSSM (Common Core Standards Writing Team, 2013), discusses K-12 representations of models that may be concrete, semi-concrete or abstract, e.g., a block structure, picture, graph, iterative or recursive equation. In introductory statistics and probability, a model could be a table, boxplot, scatterplot, or histogram. By middle/junior high school, functions may be introduced to model quantitative relationships. To enhance conceptual understanding, elementary students use rows of dots or tape diagrams to model addition and subtraction. Tape diagrams and arrays are later used to model multiplication and division. By middle/junior high school, nets can model a three-dimensional mathematical object. Physical models or geometry software can be used to model congruence and similarity. Simulations and sampling help students to understand statistical models. High school mathematics includes linear, exponential, polynomial, geometric and trigonometric models, as well as logic and logistic models such as flow charts and networks.

Although models are included at every K-12 level, teaching about models and teaching about modeling are not the same. A report of the Society of Industrial and Applied Mathematics (SIAM, 2012) stated that when a model is presented, procedures are used to allow inferences to be made concerning the model and its application. There is generally no discussion of the modeling process or how the model was derived. Without exposure to the entire modeling process, students cannot see that models develop in a way they can actually understand and construct on their own.

According to Blum, modeling is important for students because "Mathematical models and modelling are everywhere around us, often in connection with powerful technological tools. Preparing students for responsible citizenship and for participation in societal developments presupposes modelling competency."(2011, p. 19). Niss (2012) affirmed that "A major reason why mathematics is the world's single largest educational subject is the fact that mathematics is applied in a multitude of different ways in a huge variety of extra-mathematical subjects, fields and practice areas. Every time mathematics is used to deal with issues, problems, situations and contexts in domains outside of mathematics, mathematical models and modelling are necessarily involved, be it implicitly or explicitly.” (p. 49).

The MAA CUPM Modeling Course Area Report (2015) specifies that although the physical sciences and engineering have used modeling extensively,

“. . . many other disciplines have emerged as fertile ground for mathematical modeling. These areas include biology (e.g., bioinformatics, ecological studies), medicine (e.g., epidemiology, medical imaging), information science (e.g., neural networks, information assurance), sociology (e.g., social dynamics, social networks, dating/matchmaking services), political science (e.g., apportionment, social choice), business operations (e.g. operations research, resource optimization), economics (e.g., game theory, forecasting, market equilibrium), and finance (e.g., option pricing, portfolio optimization), etc." (p. 2).

English (2007) notes that elementary and middle school mathematical modeling requires the use of important "processes such as constructing, describing, explaining, predicting, and representing, together with organizing, coordinating, quantifying, and transforming data ..." (p. 142). She identifies various student formats (e.g., written text, graphs, tables, diagrams, spreadsheets, and oral reports) with multidisciplinary aspects incorporating areas such as science, history, and literature. Modeling activities often involve small-group collaborative work that requires group members to explain and justify their solutions. Children discuss questions and issues that arise as they prepare and communicate their solutions. Thus collaborative group works, and mathematical communication within multidisciplinary contexts, are related classroom concerns that teachers must be trained to effectively address and carefully assess.

Pre-service and in-service teachers must thus learn to develop and use models and modeling through training and support that is not only related to a variety of group work, but also classroom management, the teacher-facilitator 
role, classroom discourse, the selection of appropriate modeling activities, and various types of assessment (Sole, 2013). Mathematical modeling coursework has been properly included in some teacher education programs.

For student modeling activities, teachers should learn effective classroom management that is learner centered (Blum, 2011). Because such activities can be not only challenging but time intensive, aspects of student learning, assessment and use of technology should be carefully planned. Cai and colleagues (2014) suggest that the nature of instruction in mathematical modeling varies according to many factors, including educational level, curricular goals, modeling task, and teaching resources. Support in teaching modeling can involve help with traditional methods or innovative teaching practices such as inquiry methods, collaborative group based learning, and use of digital technologies.

Teacher support should include guidance in accepting the role of facilitator so that classroom instruction does not undermine the modeling goal with too much support (Blum, 2011). Model-eliciting activities (MEAs) should be carefully introduced. If they are effectively presented, tasks requiring higher levels of thinking may be beneficial to student understanding, but may otherwise impede student progress (Galbraith, Stillman, \& Brown, 2010). Training and support on the technique of scaffolding may enable teachers to appropriately assist students to complete a task without reducing its complexity (González and DeJarnette, 2015).

Group interaction can be crucial in helping students to develop mathematical thinking (González and DeJarnette, 2015). Another aspect of teacher support should thus focus on the use of small group discourse that includes teacher-group and student peer interactions occurring during the modeling process. Galbraith and colleagues (2010) find that timing is an important factor to consider because it impacts the effectiveness of a modeling task. To avoid losing appropriate focus, student classroom discourse should allow just enough time for discussion of strengths and weaknesses of their models and determination of a most feasible solution.

Pre-service and in-service teachers may simply see mathematical modeling, and student learning of mathematics through the process of mathematical modeling, as a variation of problem solving (Schoenfeld, 2013). However modeling can be more difficult than problem solving, or even unraveling intricate textbook word problems, because the real-world context for modeling may require more open and less predictable lesson formats. To develop and implement a curriculum consistent with CCSSM, it is important that teachers understand the differences between these activities. Sole (2013) enumerates significant differences:

“. . . (1) the starting point of the activity; (2) the need to differentiate between essential and non-essential variables; (3) the need to idealize the problem, and the opportunity to select the mathematical techniques applied; (4) the variety of approaches; (5) the need to transfer between the real-world and the model at the start and end of the process; and (6) the work advancing in a cyclic, rather than a linear, manner." (p. 46).

Teacher training may thus require the analysis of carefully selected examples of both good and bad MEAs.

Prospective and practicing teachers also benefit professionally when they learn the process of mathematical modeling through personal experience, even at the undergraduate or graduate level. Successful college course experiences include: data collection that enhances the ability to identify with the whole modeling process from the earliest steps; hypothesis formulation done before, during, and after developing models; computational resources used appropriately; opportunities to work in laboratories and perform experiments; presentations, dialogues and discussions that develop proficiency in modeling; and knowing strategies that enable persistence in the modeling effort (SIAM, 2012).

Because mathematical modeling does not always lead to precise answers or correct solutions, assessment can be a challenging process. Teacher training and support may thus include help with the analysis and implementation of research-based assessment recommendations, such as those presented by Blum, Frejd and Leong. Blum (2015) suggests that active learning has not only cognitive but meta-cognitive aspects. Modeling activities should thus include reflections and later retrospections, with the aim to promote learning. Assessment must appropriately reflect the aims of modeling, and diagnose student difficulties to provide appropriate help. Frejd (2013) discusses many assessment methods, such as tests, portfolios and contests - and views of modeling competencies that are either atomic or holistic. Leong (2012) suggests two ways to assess modeling tasks. The first is a scoring rubric based on analyzing aspects of each of the six steps of the CCSSM modeling cycle. The second, adapted from the field of art appreciation, analyzes the affective domain of mathematical modeling appreciation. He also discusses development of an alternative affective instrument, such as the Fenema-Sherman Mathematics Attitude Scale to measure student attitude toward mathematical modeling. 
There are two Common Core standardized assessments, one produced by the Partnership for Assessment of Readiness for College and Careers (PARCC) and another by the SMARTER Balanced Assessment Consortium (SBAC). Schoenfeld (2013) reveals that both examine four areas: concepts and procedures, problem solving, reasoning, and modeling with mathematics; but the analysis is done in different ways. He finds that the PARCC fixed-form tests provide each student a single score, but does not give the teacher or student any useful feedback. The SBAC adaptive-form tests provide separate sub-scores for each of the four areas for clearer diagnosis, intervention and follow up. A variety of teacher support is available for both the PARCC and SBAC assessments.

The MAA's CUPM Curriculum Guide to Majors in the Mathematical Sciences (Zorn, 2015) lists several Course Areas, including one for Modeling. The Modeling CASG agreed that modeling is an essential component of the K-12 mathematics curriculum. The CASG Modeling report (2015) recommends that ". . . colleges and universities that prepare future teachers will want to ensure that their mathematics curriculum is configured in such a way that preservice teachers gain meaningful experience with modeling and applications of mathematics, either through modeling activities integrated into the core mathematics curriculum, through a dedicated course focused on mathematical modeling, or both." (p. 8)

The Guide stipulates that the primary purpose of any modeling course is to enable students to transfer their knowledge and use of mathematical models to solve future problems. According to the Guide, the general course objectives in teaching modeling as a transferable process are (1) introduce components of the mathematical modeling process; (2) use an applications-based approach; (3) highlight the utility of the mathematics required; and (4) establish the relation between different mathematical topics.

Cai and colleagues (2014) found that researchers worldwide have developed mathematical modeling courses. Some teacher education programs have included mathematical modeling as part of their requirements. A general approach, as later resounded in the Guide, is to use modeling activities to develop mathematics skills and concepts for use in further applications. Several professional development programs for in-service teachers have been part of funded projects of fixed duration with research and evaluation components contingent on successful completion within a given time frame.

Ferri (2013) describes a noteworthy example funded by the European Union, the LEMA Project (Learning and Education in and through Modelling and Applications). Six European nations (Germany, Spain, Hungary, Greece, France, and the United Kingdom) participated in order to facilitate changes that promote classroom mathematical modeling activities. During the three-year project, the LEMA team analyzed teachers' needs by examining their beliefs about mathematics, tasks they used, and opinions about modeling tasks. Project results showed that teachers are aware of mathematics applications, but prefer not to use modeling tasks because such tasks are too difficult for their students and time consuming. Thus LEMA materials were developed in a modular structure for use in different countries at both primary and secondary levels. The materials include a teacher training course. The LEMA team piloted the course material during 2008 with more than 120 teachers from Cyprus, England, France, Germany, Hungary, and Spain. Course evaluation results show a significant increase in PCK and self-efficacy in relation to modeling, and in teacher intentions to include modeling in their lessons. An enhanced version of the materials was made available in various countries in Europe. The LEMA Project exemplifies the extent of teacher training and support needed to promote mathematical modeling in European classrooms, but clearly has further implications.

3.3 Professional Development of In-service Teachers That Recognizes Their Diverse Academic and Professional Expertise, and Provides Ways to Improve and Support Their Understanding of Mathematical Modeling, Including Teaching and Assessing It

The educational backgrounds of mathematics teachers in the United States vary widely, especially because requirements for teaching at different levels are not the same and because the criteria for teacher licensure have changed. An important consideration in examining teacher background in mathematical modeling is thus educational preparation. Research also suggests that teachers with different disciplinary backgrounds may be teaching about mathematical models and modeling in different ways. Better analysis of teacher backgrounds can inform teacher trainers about the diversity of teacher ideas about models and modeling, so that common understanding of terminology is not assumed (Bautista, Wilkerson-Jerde, Tobin, \& Brizuela, 2014).

Mischo and Maaß (2013) note that teacher beliefs about mathematical modeling can be classified as static or process. Teachers with beliefs that are static think of it as an exact and formal process, with a collection of rules and formulas to be applied. In contrast, teachers with beliefs of the process type think of mathematical modeling as a generative and creative process relevant for society, and thus look for the best solutions to real-life problems. 
These contrary beliefs can lead to conflicting expectations and classroom modeling that vacillates from the CCSSM curriculum.

The SIAM report (2014) discussed the results of doctoral dissertation research by a Columbia University student, Heather Gould. Her 2013 study examined teacher beliefs and misconceptions about mathematical models and modeling. Gould found that a majority of teachers correctly believed that mathematical modeling can generate equations or formulas; can be used to explain causation; involves determining if a solution makes sense; and may involve either repetition or revision of steps, or both, in the solution. Gould also found a majority of the teachers incorrectly believed that mathematical models can be physical manipulatives such as fraction tiles or pattern blocks; that modeling can involve unrealistic scenarios; always results in the exact answer(s); and does not involve making choices and assumptions. Clearly professional development must identify, address and clarify teacher misconceptions before they become student misconceptions about mathematical modeling.

To effectively teach modeling, Blum (2015) noted that a teacher requires many different competencies. As an example, he used the competence model from the Cognitively Activating Instruction, and Development of Students' Mathematical Literacy (COACTIV) project. Kunter et al (2013) analyze COACTIV categories that include content knowledge (CK), pedagogical content knowledge (PCK), and pedagogical/psychological knowledge (PK). Research-based teacher training consistently recommends strong support in both subject matter knowledge and pedagogical content knowledge.

Teachers also benefit from an opportunity to review student work, including a student's multiple solutions for a given modeling task, in order to better understand student learning and to develop lessons that are cognitively appropriate (Schukajlow \& Krug, 2013). The analysis of student thinking is a significant part of preparing teachers to confront a variety of student responses that are inherent in mathematical modeling activities (Pollak, 2012). Teachers need to evaluate student ideas quickly, and determine the reason behind student errors, to effectively manage mathematical modeling tasks (Ball et al., 2008). Professional development should include grade appropriate examples of mathematics modeling lessons. There should also be variation in the real-world contexts, mathematical contexts and topics (Pollak, 2012).

Teachers with little mathematical modeling experience may find it very challenging because it requires significant time and effort. Even teachers with more modeling experience may be reluctant to use modeling activities because of the level of difficulty or the demands on class time. Clearly professional development must show how modeling activities can be adapted to accommodate a variety of student abilities, designed to integrate several curricular standards, and thus actually maximize efficient use of class time (Pollak, 2012). The SIAM report (2014) also suggested making connections between the CCSSM critical thinking and modeling practices, and student preparation for standardized assessment tests. "Well-designed experience in mathematical modeling promotes critical thinking, thus students are likely to perform better on tests and other kinds of analytical tasks."(p. 23).

The SIAM report (2014) noted that, in general, the elements of successful professional development include multiple meetings over a long period, lesson creation and lesson study, reflection tasks, pre and post assessment, and dissemination (p.15). However, the report questioned whether such professional development can truly compensate for sorely inadequate university/teacher college course offerings in mathematical modeling.

The most common formats of local and regional professional development programs are the workshop, seminar, webinar, colloquium and the summer institute, with program lengths that vary with the format. Professional development programs may be university affiliated and may include a network of experts for mentoring, peer support, inquiries and discussion. Teacher resources may be online and include open courseware, video vignettes, classroom activities, related content information and web sites for additional background information. There may also be social networking available for teachers with urgent classroom questions or information to share. Two exemplary online resources providing teacher support are (1) from the Consortium for Mathematics and Its Applications (COMAP), Mathematics: Modeling Our World (MMOW),

http://www.comap.com/highschool/projects/mmow/ and (2) from the National Council of Teachers of Mathematics (NCTM), Core Math Tools, http://www.nctm.org/coremathtools/.

Many professional organizations (e.g., Society for Industrial and Applied Mathematics, American Mathematical Society, American Statistical Association, International Congress of Mathematicians, Institute of Electrical and Electronics Engineers, Mathematical Association of America, and Association of Computing Machinery) support classroom activities that promote mathematical modeling. Teacher resources are also provided through a variety of programs designed to improve preparation for students in STEM areas of study. These include high school teamwork and modeling competitions such as those sponsored by SIAM and COMAP (SIAM, 2012). 
Research shows that technology can be a powerful tool for modeling activities (Greefrath, 2011). Computers can be used for experiments, investigations, simulations, visualizations and calculations. Statistics and geometry software and apps, CBLs (Calculator-Based Laboratories) and CBRs (Calculator-Based Rangers) have all proven helpful. Because MEAs can be multidisciplinary, other software and apps may prove viable. Faculty development programs should thus include a broad technology component.

Some resources, such as the Mathematical Modeling Handbook (Pollak, 2012) exemplify the research-based activities and experiences to support and improve MKT in mathematical modeling. Although written to provide CCSSM-aligned high school lessons, the Handbook is recommended for use in undergraduate teacher education programs, pre- and in-service training programs, and professional development. The Handbook begins with a task to guide teachers of diverse backgrounds and experiences to a clear understanding of mathematical modeling. Teachers are directed to analyze the progression of the Handbook's 26 modules to see how they and their students are led to think like mathematicians, and thus come to better understand the modeling process. Subsequent activities for teachers include: adapting MEAs to the needs of different students; anticipating how students will respond to lesson questions and tasks; identifying the most challenging questions and devising appropriate student support; finding ways to help struggling students persevere in developing a model; searching for valid alternative mathematical models and for lessons that can be taught from multidisciplinary perspectives (e.g., science or social studies); collaborating and developing plans to facilitate classroom implementation of the MEAs.

In the Handbook mathematical modeling is described as both a procedure and a cognitive process, and thus difficult to assess. A final professional development task suggests further teacher collaboration to determine the best way to assess students, by both formative and summative means.

\section{Discussion and Conclusion}

This research found worldwide variety in the ways that education and training can support pre-service and in-service teachers with regard to mathematical modeling. Educational recommendations included MKT, updated as TPACK, with content, pedagogy and technology components; and four special dimensions (theoretical competency, task related competency, teaching competency and diagnostic competency) of mathematical knowledge specifically for modeling. Advised undergraduate coursework in mathematical modeling may be integrated into the college mathematics curriculum, through a mathematical modeling course, or both. Teacher training coursework should clarify fundamentals such as what a mathematical model is, why mathematical modeling is important and what classroom strategies and challenges may be involved in the K-12 development, use and assessment of mathematical modeling. Such education and training helps to avoid having teachers with different disciplinary backgrounds teach about mathematical models and modeling in ways that conflict with one another, with CCSSM guidelines, or both.

The research included professional development activities with pertinent suggestions such as acknowledging the diversity of teacher backgrounds, beliefs and preparedness in mathematics, especially in mathematical modeling; and selecting ways to build upon it to improve their expertise in mathematical modeling. Although components of successful professional development programs are discussed, the research does not reveal one perfect method or set of techniques that can prepare each individual teacher to effectively teach mathematical modeling as a transferable process. Professional development must thus help each in-service teacher in clearly defining mathematical modeling; actually developing, doing and assessing mathematical modeling activities; in learning not only appropriate pedagogical strategies but modern multidisciplinary content; and in successfully utilizing his/her academic background and professional expertise as unique resources to learn how to best facilitate mathematical modeling in the classroom.

Since teachers spend so much time as students before they begin their careers, research generally shows that they tend to teach as they are taught. Future U.S. research may reveal that this is even the case with a cycle generated by improved learning and better teaching of mathematical modeling, perhaps also resulting in notably reduced or nonexistent teacher and student misperceptions, and greater appreciation for important interdisciplinary connections that emerge in the study of mathematics. Since teachers must learn the facilitator role during mathematical modeling in the classroom, it appears they should be able to draw upon experiences with teacher educators, trainers and mentors who have assumed an exemplary facilitator role during mathematical modeling in teacher education coursework and professional development. Further research may also be required to identify and confirm specific aspects of this exemplary facilitator role that can actually improve how mathematical modeling is later taught. 
While the primary focus of this research is on teacher education and training in mathematical modeling in the United States, the findings from both domestic and international research are clearly significant for those who are responsible for various aspects of teacher preparation in many localities.

\section{References}

Ball, D. L., Thames, M. H., \& Phelps, G. (2008). Content knowledge for teaching what makes it special?. Journal of teacher education, 59(5), 389-407. http://dx.doi.org/10.1177/0022487108324554

Bautista, A., Wilkerson-Jerde, M. H., Tobin, R. G., \& Brizuela, B. M. (2014). Mathematics teachers' ideas about mathematical models: a diverse landscape.

Blum, W. (2011). Can modelling be taught and learnt? Some answers from empirical research. In Kaiser, G., Blum, W., Borromeo Ferri, R., \& Stillman, G. (Eds.). Trends in Teaching and Learning of Mathematical Modelling (p. 15-30). Springer, New York. http://dx.doi.org/10.1007/978-94-007-0910-2_3

Blum, W. (2015). Quality Teaching of Mathematical Modelling: What Do We Know, What Can We Do?. In The Proceedings of the 12th International Congress on Mathematical Education (pp. 73-96). Springer International Publishing. http://dx.doi.org/10.1007/978-3-319-12688-3_9

Cai, J., Cirillo, M., Pelesko, J. A., Borromeo Ferri, R., Borba, M., Geiger, V., . . . \& Kwon, O. N. (2014). Mathematical modeling in school education: mathematical, cognitive, curricular, instructional and teacher education perspectives. In Proceedings of the Joint Meeting of PME 38 and PME-NA 36 (Vol. 1, pp. 145-172). PME-NA.

Common Core Standards Writing Team. (2013, July 4). Progressions for the Common Core State Standards in Mathematics (draft). High School, Modeling.Tucson, AZ: Institute for Mathematics and Education, University of Arizona.

Common Core State Standards Initiative. (2010). Common Core State Standards for Mathematics (CCSSM). Washington, DC: National Governors Association Center for Best Practices and the Council of Chief State School Officers.

English, L. D. (2007). Complex systems in the elementary and middle school mathematics curriculum: A focus on modeling. Festschrift in Honor of Gunter Torner. The Montana Mathematics Enthusiast, 139-156.

Ferri, R. B. (2013). Mathematical Modelling in European Education. Journal of Mathematics Education at Teachers College, 4(2).

Ferri, R. B., \& Blum, W. (2009). Mathematical modelling in teacher education-experiences from a modelling seminar. CERME 6-WORKING GROUP 11, 2047.

Frejd, P. (2013). Modes of modelling assessment — a literature review. Educational Studies in Mathematics, 84(3), 413-438. http://dx.doi.org/10.1007/s10649-013-9491-5

Galbraith, P. L., Stillman, G., \& Brown, J. (2010). Turning ideas into modeling problems. In Modeling students' mathematical modeling competencies (pp. 133-144). Springer US. http://dx.doi.org/10.1007/978-1-4419-0561-1_11

González, G., \& DeJarnette, A. F. (2015). Teachers' and Students' Negotiation Moves When Teachers Scaffold Group Work. Cognition and Instruction, 33(1), 1-45. http://dx.doi.org/10.1080/07370008.2014.987058

Greefrath, G. (2011). Using technologies: New possibilities of teaching and learning modelling-Overview. In Trends in Teaching and Learning of Mathematical Modelling (pp. 301-304). Springer Netherlands. http://dx.doi.org/10.1007/978-94-007-0910-2_30

Kunter, M., Baumert, J., Blum, W., Klusmann, U., Krauss, S., \& Neubrand, M. (Eds.). (2013). Cognitive activation in the mathematics classroom and professional competence of teachers: Results from the COACTIV project. Springer Science \& Business Media. http://dx.doi.org/10.1007/978-1-4614-5149-5

Leong, K. E. (2012). Assessment of Mathematical Modeling. Journal of Mathematics Education at Teachers College, 3(1), 61-65.

Mischo, C., \& Maßß, K. (2013). The Effect of Teacher Beliefs on Student Competence in Mathematical Modeling-An Intervention Study. Journal of Education and Training Studies, 1(1), p19-38. http://dx.doi.org/10.11114/jets.v1i1.24

Modeling Course Area Report (2015), a report of the Mathematical Association of America, Committee on the Undergraduate Program in Mathematics, Course Area Study Group (CASG) on modeling, Retrieved from 
http://www2.kenyon.edu/Depts/Math/schumacherc/public_htm1/Professional/CUPM/2015Guide/Course\%2 0Groups/modeling.pdf

National Council of Teachers of Mathematics (Ed.). (2000). Principles and standards for school mathematics (Vol. 1). Reston, VA: National Council of Teachers of Mathematics.

National Council of Teachers of Mathematics. (2006). Curriculum focal points for prekindergarten through grade 8 mathematics: A quest for coherence. Reston, VA: National Council of Teachers of Mathematics. Retrieved from https://www2.bc.edu/solomon-friedberg/mt190/nctm-focal-points.pdf

National Research Council. The Mathematical Sciences in 2025. (2013). Washington, DC: The National Academies Press. Retrieved from www.nap.edu/catalog.php?record_id=15269.

Niess, M. L. (2015). Transforming Teachers' Knowledge: Learning Trajectories for Advancing Teacher Education for Teaching with Technology. In Technological Pedagogical Content Knowledge (pp. 19-37). Springer US. http://dx.doi.org/10.1007/978-1-4899-8080-9_2

Niss, M. A. (2012). Models and modelling in mathematics education. European Mathematical Society. Newsletter, $86,49-52$.

Pollak, H. O. (2012). Introduction - What is Mathematical Modeling?. In Gould, H., Murray, D. R., \& Sanfratello, A (Eds.), Mathematical Modeling Handbook (pp. viii-xi), Bedford, MA: The Consortium for Mathematics and Its Applications. Retrieved from www.comap.com.

President's Council of Advisors on Science and Technology. (2012). Report to the President Engage to Excel: Producing One Million Additional College Graduates with Degrees in Science, Technology, Engineering, and Mathematics. Washington, DC: Executive Office of the President. Retrieved from http://www.whitehouse.gov/sites/default/files/microsites/ostp/pcast-engage-to-excel-final_2-25-12.pdf.

Schukajlow, S., \& Krug, A. (2013). Considering multiple solutions for modelling problems-design and first results from the MultiMa-Project. In Teaching Mathematical Modelling: Connecting to Research and Practice (pp. 207-216). Springer Netherlands. http://dx.doi.org/10.1007/978-94-007-6540-5_18

Schoenfeld, A. H. (2013). Mathematical modeling, sense making, and the common core state standards. Journal of Mathematics Education at Teachers College, 4(2).

Society for Industrial and Applied Mathematics (2012). SIAM Modeling across the Curriculum: Report on a SIAM-NSF Workshop. Philadelphia, PA: Society for Industrial and Applied Mathematics. Retrieved from http://www.siam.org/reports/modeling_12.pdf.

Society for Industrial and Applied Mathematics (2014). SIAM Modeling across the Curriculum II: Report on the second SIAM-NSF Workshop. Philadelphia, PA: Society for Industrial and Applied Mathematics. Retrieved from https://www.siam.org/reports/modeling_14.pdf

Sole, M. (2013). A Primer for Mathematical Modeling. Journal of Mathematics Education at Teachers College, $4(2)$.

Zorn, P. (Ed.) (2015). Undergraduate Programs and Courses in the Mathematical Sciences: CUPM Curriculum Guide, 2015. Mathematical Association of America. 1529 Eighteenth Street NW, Washington, DC 20036-1358. http://www.maa.org/sites/default/files/pdf/CUPM/pdf/CUPMguide_print.pdf.

\section{Copyrights}

Copyright for this article is retained by the author(s), with first publication rights granted to the journal.

This is an open-access article distributed under the terms and conditions of the Creative Commons Attribution license (http://creativecommons.org/licenses/by/3.0/). 